\title{
Oversights, Confusions and Misinterpretations Related to Self-Care and Medication in Diabetic and Renal Patients
}

\author{
José J. Mira ${ }^{a-c}$ Lidia Ortiz $^{a} \quad$ Susana Lorenzo ${ }^{d}$ Catalina Royuela ${ }^{d}$ \\ Julián Vitaller ${ }^{\mathrm{a}, \mathrm{e}}$ Virtudes Pérez-Jover ${ }^{\mathrm{a}}$ \\ ${ }^{a}$ Miguel Hernández University, Elche, ${ }^{b}$ Alicante/San Juan Health District, Consellería Sanitat, Generalitat Valenciana, \\ Alicante, ${ }^{\mathrm{C}}$ Research Network on Health Services in Chronic Diseases (REDISSEC), ${ }^{\mathrm{d}}$ Hospital Universitario Fundación

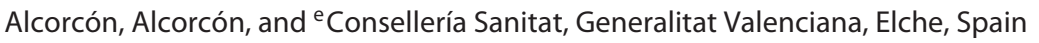

\section{Key Words}

Patient safety - Medication errors · Patient participation .

Physician-patient relations

\begin{abstract}
Objective: To analyse information about the errors made by diabetic and renal patients based on information provided by professionals (general practitioners, specialists, and nurses) and the patients themselves. Subjects and Methods: A descriptive study was carried out by interviewing 199 patients and 60 professionals from the Spanish provinces of Alicante and Madrid. The interview explored the frequencies and types of oversights, confusions, and misinterpretations and the factors that contributed to them. Results: Among the 199 patients, $59(29.5 \%)$ and 42 (70\%) of the 60 professionals considered that patients frequently made errors that affected the success of their treatment. There were no differences in the frequency of the reported errors based on gen$\operatorname{der}(p=0.7)$, educational level $(p=0.9)$, or marital status $(p=0.5)$. The most commonly reported errors were taking the wrong medication $(n=70 ; 35 \%)$ and mixing up medicines $(n=15 ; 7.5 \%)$. Diabetics who had not been adequately informed, compared to renal patients, reported a higher number of errors $(p=0.02)$. Conclusions: Patient errors were
\end{abstract}

frequent because of communication failures and confusions. Diabetic patients had a higher chance of committing an error than renal patients. Patient education must include clear and personalized instructions for improving self-care and reducing risks when using medicines.

(c) 2014 S. Karger AG, Basel

\section{Introduction}

Although 5\% of hospital admissions are due to medication errors committed by patients [1], to date there are few studies on the errors patients make in the course of their treatments [2-7]. Identifying the most frequent patient errors (action and mental category errors) [8] could be useful for standardizing the information that professionals (or medication leaflets) should provide to patients, with a view to foreseeing these sources of risk, but also for guiding the work of patients' associations, which are showing an increasing interest in active intervention in healthcare quality improvement.

Previous studies on patient safety have revealed two risk factors which are intrinsic to the occurrence of an adverse event $[9,10]$ : diabetes (present in $17 \%$ of cases) and kidney failure (present in $12 \%$ of cases). Thus, the

\begin{tabular}{ll}
\hline KARGER & $\begin{array}{l}\text { () 2014 S. Karger AG, Basel } \\
1011-7571 / 14 / 0233-0246 \$ 39.50 / 0 \quad \text { Karger }\end{array}$ \\
$\begin{array}{l}\text { E-Mail karger@karger.com } \\
\text { www.karger.com/mpp }\end{array}$ & $\begin{array}{l}\text { This is an Open Access article licensed under the terms of the } \\
\text { Creative Commons Attribution-NonCommercial 3.0 Un- } \\
\text { ported license (CC BY-NC) (www.karger.com/OA-license), } \\
\text { applicable to the online version of the article only. Distribu- } \\
\text { tion permitted for non-commercial purposes only. }\end{array}$
\end{tabular}

José Joaquín Mir

Miguel Hernández University

Altamira Building, Avd Universidad s/n

ES-03202 Elche (Spain)

E-Mail jose.mira@umh.es 
characteristics of these diseases and their treatment modalities indicate that there is more room for the improvement of safety than in other cases. On the other hand, recent studies have shown that patients could collaborate as vigilant partners to avoid adverse events [3], and that they must be alert to their own errors related to medication or self-care. Hence, the objective of this study was to collect information about the errors made by diabetic and renal patients on the basis of information provided by professionals and by the patients themselves.

\section{Subjects and Methods}

A descriptive study of oversights, confusions, misinterpretations or mistakes (considered in this study as errors) in relation to the self-administration of medication and self-care in the last year was carried out at 3 health centres (Mutxamiel, El Cabo and Raval) and 2 hospitals in Alicante (General Hospital) and Madrid (Hospital of Alcorcón). In this study, structured interviews were conducted with diabetic patients on insulin treatment or patients with kidney failure undergoing dialysis treatment (with the two samples being mutually exclusive) and with physicians and nurses who had experience in treating these pathologies. The patients and professionals were interviewed to identify the most common sources and types of patient errors and the factors contributing to them. The term patient error was used in a broad sense to include confusions, omissions, oversights, misinterpretations and mistakes (e.g. confusing medication or taking the wrong dose). This study was approved by the Research Committee of Miguel Hernández University, Elche, Spain.

\section{Qualitative Research: Interviews}

A total of 28 in-depth interviews were carried out between May and October 2009 to identify the characteristics of the errors seen by professionals and patients, as well as patients' misunderstandings that have an effect on patient safety. This questionnaire was based on two Spanish nationwide studies on adverse events in hospital and primary care, i.e. ENEAS [9] and APEAS [10], the Agency for Healthcare Research and Quality (AHRQ) [11], the UK National Health System [12] and the Patient Safety Perception Questionnaire validated in Spain.

Four interviews were carried out with primary care doctors, 5 interviews with specialists in nephrology, 3 with primary care nurses, 4 with haemodialysis and dialysis nurses and 12 with patients ( 6 diabetics and 6 with kidney failure). For the professionals, the inclusion criterion was a minimum of 5 years' experience and the exclusion criterion was involvement in civil cases filed in court by caregivers in the past 5 years. For the patients, the inclusion criteria were more than 3 years' duration of the illness, insulin or dialysis treatment according to the patient's profile and being capable of providing information. The exclusion criteria were having filed some kind of lawsuit or having made more than 3 complaints to the patient support service in the last 3 years. The responses were used to design an inventory of the frequencies and types of errors so as to identify patient errors and the factors contributing to them.
Table 1. Descriptive data of the patient sample

\begin{tabular}{lcc}
\hline & $\begin{array}{l}\text { Diabetes }^{\mathrm{a}} \\
(\mathrm{n}=99)\end{array}$ & $\begin{array}{l}\text { Kidney failure }^{\mathrm{b}} \\
(\mathrm{n}=101)\end{array}$ \\
\hline Age, years & $54.1 \pm 20.7$ & $61.7 \pm 15.6$ \\
Time in treatment, years & $14.4 \pm 11.3$ & $4.8 \pm 6.1$ \\
Women & $50(50.5)$ & $51(50.5)$ \\
Marital status & & $17(16.8)$ \\
$\quad$ Single & $24(24.2)$ & $63(63.4)$ \\
$\quad$ Married & $48(48.5)$ & $14(13.9)$ \\
$\quad$ Widowed & $22(22.2)$ & $7(6.9)$ \\
$\quad$ Divorced & $5(5.1)$ & $66(73.3)$ \\
Education & $63(61.6)$ & $15(16.7)$ \\
$\quad$ Elementary & $24(24.2)$ & $9(10.0)$ \\
$\quad$ Technical/vocational & $14(14.1)$ & \\
\hline
\end{tabular}

Values are presented as means \pm SD or numbers (\%). ${ }^{a}$ Insulin treatment. ${ }^{\mathrm{b}}$ Dialysis treatment.

Quantitative Research: Surveys of Patients and Professionals

A minimum of 100 diabetic patients on insulin treatment, 100 patients with renal failure and 50 physicians or nurses were surveyed with the inventory of patient errors between February and May 2010 in the provinces of Alicante and Madrid.

The inventory of patient errors showed Cronbach's alphas ranging from 0.72 to 0.75 and Jöreskog-Sörbom fit indexes ranging from 0.89 to 0.91 for diabetes and renal failure, respectively.

Patients who visited any of the 3 health centres and 2 hospitals for a consultation or treatment were selected at random. Informed consent was obtained from all participants. The 3 interviewers were instructed to favour patients' spontaneous answers. The sample size was calculated for an error of $5.8 \%$ for a $\mathrm{p}=\mathrm{q}=0.5$ and an alpha of 0.05 (unilateral) for the whole sample. The aggregate number of errors made was calculated.

A convenience-based sample of professionals was obtained from the lists of national and regional scientific and professional associations. They were invited to participate via e-mail, and care was taken to avoid disrupting their consultation agendas. The recruitment criteria for the professionals were employment as specialists in family and community medicine, nephrology or endocrinology, and nurses from haemodialysis or dialysis units with at least 3 years' professional experience; it was essential that they had not been reported by patients (civil cases) in the last 5 years.

\section{Statistical Analysis}

To detect differences between categorical variables, the $\chi^{2}$ test was used. For the professionals' responses, we considered the percentage of responses $\geq 8$ and the variation coefficient (SD/ mean). In the interpretation of the statistics, $\mathrm{p}<0.05$ was considered statistically significant. SPSS version 19.0 (SPSS, Inc., Chicago, Ill., USA) was used for this analysis. 
Table 2. Patients' and professionals' points of view regarding the frequency of errors made by patients

\begin{tabular}{|c|c|c|c|c|c|c|}
\hline & \multicolumn{2}{|l|}{ Total } & \multicolumn{2}{|l|}{ Diabetes $^{\mathrm{a}}$} & \multicolumn{2}{|c|}{ Kidney failure ${ }^{\mathrm{b}}$} \\
\hline & $\begin{array}{l}\text { patients } \\
(\mathrm{n}=199)\end{array}$ & $\begin{array}{l}\text { professionals } \\
(\mathrm{n}=60)\end{array}$ & $\begin{array}{l}\text { patients } \\
(\mathrm{n}=98)\end{array}$ & $\begin{array}{l}\text { professionals } \\
(\mathrm{n}=33)\end{array}$ & $\begin{array}{l}\text { patients } \\
(\mathrm{n}=101)\end{array}$ & $\begin{array}{l}\text { professionals } \\
(\mathrm{n}=27)\end{array}$ \\
\hline Frequent & $59(29.5)$ & $42(70)$ & $43(43.4)$ & $25(75.8)$ & $16(15.8)$ & $17(63.0)$ \\
\hline Not very frequent & $94(47)$ & $17(28.3)$ & $41(41.4)$ & $7(21.2)$ & $53(52.5)$ & $10(37)$ \\
\hline Rare & $32(16)$ & $1(1.7)$ & $10(10.1)$ & $1(3)$ & $22(21.8)$ & 0 \\
\hline \multirow[t]{2}{*}{ Do not know/no answer } & $15(7.5)$ & 0 & $5(5.1)$ & 0 & $10(9.9)$ & 0 \\
\hline & \multicolumn{2}{|c|}{$\chi^{2}=29.2, p<0.0001$} & \multicolumn{2}{|c|}{$\chi^{2}=9.0, p=0.01$} & \multicolumn{2}{|c|}{$\chi^{2}=23.6, p<0.0001$} \\
\hline
\end{tabular}

Values are presented as numbers (\%) and refer to the frequency of errors committed by the patients themselves that affected the treatment course (caused them harm or resulted in a need for additional treatment). Errors include oversights, confusions and misinterpretations. ${ }^{\text {a }}$ Insulin treatment. ${ }^{\mathrm{b}}$ Dialysis treatment.

\section{Results}

Two hundred patients (99 diabetics on insulin treatment and 101 renal patients undergoing dialysis treatment) and 60 professionals (GPs, specialists and dialysis unit nurses) responded to the interviews (table 1). One diabetic patient could not finish the interview, so his responses were discarded. The respondents were 6 advisors (endocrinology and nephrology specialties), 45 specialists (2 endocrinologists, 3 nephrologists and 40 GPs), 4 nurses from primary care, 4 dialysis nurses and 1 nurse from a nephrology ward.

\section{Frequency of Patient Errors}

Of the 199 patients interviewed, 59 (29.5\%) reported making some type of error frequently (table 2), while 42 (70\%) of the 60 professionals reported that patients frequently made errors that caused harm to them or resulted in a need for additional treatment. Of the 199 patients, $126(63 \%)$ believed that patients did not make errors in the course of their treatment and they also tended to believe that the frequency of medical errors was low $\left(\chi^{2}=\right.$ $27.3, \mathrm{p}=0.0001)$. The longer the patients had been in treatment, the more likely they were to think that they had frequently made errors which caused harm or treatment complications (mean 13.4 years, $\mathrm{p}=0.04$ ). The frequency of patients reporting that they themselves made errors did not vary significantly according to gender $(p=0.7)$, educational level $(\mathrm{p}=0.9)$ or marital/relationship status $(\mathrm{p}=$ $0.5)$. The proportion of patients who tended to believe that patients make fewer errors in the course of their treatment was higher among patients who used pillboxes to sort out their medicines (23/59 vs. $36 / 59 ; \chi^{2}=11.2$, $\mathrm{p}=$
Table 3. Common patient errors in the last year of treatment (aggregate data)

\begin{tabular}{llll}
\hline Errors & $\begin{array}{l}\text { Diabetes }^{\mathrm{a}} \\
(\mathrm{n}=98)\end{array}$ & $\begin{array}{l}\text { Kidney failure }^{\mathrm{b}} \\
(\mathrm{n}=101)\end{array}$ & $\begin{array}{l}\text { Total } \\
(\mathrm{n}=199)\end{array}$ \\
\hline 0 & $12(12.2)$ & $61(60.4)$ & $73(36.7)$ \\
1 & $16(16.3)$ & $25(24.8)$ & $41(20.6)$ \\
2 & $18(18.4)$ & $11(10.9)$ & $29(14.6)$ \\
3 & $17(17.3)$ & $3(3)$ & $20(10.0)$ \\
$\geq 4$ & $35(35.8)$ & $1(1)$ & $34(17.1)$ \\
\hline
\end{tabular}

Values are presented as numbers (\%). ${ }^{\mathrm{a}}$ Insulin treatment. ${ }^{\mathrm{b}} \mathrm{Di}-$ alysis treatment.

$0.004)$ and among those who visited their doctor accompanied by a family member $\left(22 / 59\right.$ vs. $37 / 59 ; \chi^{2}=9.2, \mathrm{p}<$ 0.01 ). On the contrary, the proportion of patients who thought patients make errors more frequently was higher among patients who reported during the interview that their doctors were accessible and that they could ask them about their doubts and concerns $\left(36 / 59\right.$ vs. $23 / 59 ; \chi^{2}=7.9$, $\mathrm{p}=0.02)$ and among those who stated that they could go over what they were going to say before their doctor's appointment $\left(32 / 59\right.$ vs. $\left.27 / 59 ; \chi^{2}=12.6, p=0.002\right)$.

\section{Patients' Point of View}

Of the 98 diabetic patients, 57 (58.2\%) reported having experienced hypoglycaemia due to errors with medication or food; $32(32.7 \%)$ had developed blisters, wounds or infection due to wearing the wrong footwear; 27 $(27.6 \%)$ reported having eaten proscribed food with the medication, and 23 (23.5\%) reported difficulties with ad- 
Table 4. Most frequent errors committed by patients according to professionals

\begin{tabular}{|c|c|c|c|c|c|c|}
\hline \multicolumn{3}{|c|}{$\begin{array}{l}\text { Errors of the diabetics } \\
(\mathrm{n}=33)\end{array}$} & \multicolumn{4}{|c|}{$\begin{array}{l}\text { Errors of the kidney failure } \\
\text { patients }(n=27)\end{array}$} \\
\hline mean $^{\mathrm{a}}$ SD & $\mathrm{VC}$ & $\begin{array}{l}\geq 8 \text { points }^{\mathrm{b}}, \\
\%\end{array}$ & mean $^{\mathrm{a}}$ & SD & $\mathrm{VC}$ & $\begin{array}{l}\geq 8 \text { points }{ }^{\mathrm{b}}, \\
\%\end{array}$ \\
\hline
\end{tabular}

Taking the wrong medicine

Simultaneously taking two medications that interact with one another

Taking an incorrect dose

$\begin{array}{llll}6.9 & 2.3 & 0.33 & 39.4\end{array}$

$\begin{array}{llll}6.4 & 2.4 & 0.38 & 42.4\end{array}$

$\begin{array}{llll}6.3 & 2.3 & 0.37 & 33.3\end{array}$

Ingestion of food incompatible with the medication

6.3

Failure to use the correct dose of phosphorus chelants

Confusion regarding what doctors or nurses have told patients

Failure to follow the recommended diet (types of food or amounts eaten per day)

$\begin{array}{llll}8.3 & 1.3 & 0.16 \quad 81.8\end{array}$

Misunderstanding what the doctors or nurses have explained

Use of the wrong footwear

Oversights in relation to foot care and check-ups

$\begin{array}{llll}7.4 & 1.6 & 0.22 & 45.5\end{array}$

Failure to carry out the blood pressure and weight checks

correctly at home

$\begin{array}{llll}7.6 & 1.6 & 0.21 & 60.6\end{array}$

Mixing up drugs due to their appearance or colour

Confusion in relation to the medication to be taken (e.g. confusing drugs due to similar shapes or colours)

$\begin{array}{llll}6.1 & 1.9 & 0.31 & 27.3\end{array}$

$\begin{array}{lll}6.4 & 2.4 & 0.38\end{array}$

26.9

\section{Others}

Abandonment of treatment if the glucose test result improves

favourably

$\begin{array}{llll}6.7 & 1.6 & 0.24 & 30.3\end{array}$

Poor control over medication or inappropriate food intake

resulting in hypoglycaemia

$\begin{array}{llll}6.4 & 2.1 & 0.33 & 30.3\end{array}$

Failure to inform the health professional about personal risk

situations (e.g. allergies, work situation or other treatments

with other doctors)

Once the blood pressure is under control, discontinuing

treatment despite not being told to do so by the doctor

$\begin{array}{llllllll}6.4 & 2.2 & 0.34 & 39.4 & 7.1 & 2.1 & 0.30 & 46.2 \\ - & & & & 6.5 & 2.7 & 0.42 & 34.6\end{array}$

$\mathrm{VC}=$ Variation coefficient (ranging from 0 to 1 , where a value close to 1 implies that the professionals have different points of view on whether this aspect is a common source of errors). ${ }^{a}$ On a scale of 0 (never or not at all common) to 10 (occurred in almost all patients). ${ }^{\mathrm{b}}$ On a scale of $0-10$; the percentage of professionals assigning 8 scale points or more to each aspect complements the information for determining which factors constitute the basic determinants of patient errors.

justing their insulin dose correctly. Diabetic patients who reported that they had not been informed about possible side effects and precautions $(n=57 ; 29.2 \%)$ reported the largest number of errors ( 3.9 vs. 2.7 ; $\mathrm{t}$ test $=-2.4, \mathrm{p}=0.02$ ).

Of the 101 renal patients on dialysis, $19(18.8 \%)$ reported that they occasionally forgot to take their pills, and $5(5 \%)$ did not control the vascular catheter properly.

Of the 199 patients, 70 (35\%) reported taking the wrong medicine as the most frequent error $[\mathrm{n}=46(46.9 \%)$ for diabetic patients vs. $\mathrm{n}=24$ (23.8\%) for renal failure patients $(\mathrm{p}=0.01)]$, followed by mixing up drugs due to their appearance or colour [reported by 15 (7.5\%) pa- tients, i.e. $\mathrm{n}=12(12.2 \%)$ for diabetic patients vs. $\mathrm{n}=3$ $(3.0 \%)$ for renal failure patients $(\mathrm{p}=0.03)]$.

Of the 101 renal patients, $60(60 \%)$ reported that they had never committed any of the most frequently identified errors compared to 12 (12\%) of the 98 diabetic patients. Four percent of renal patients, compared to $43 \%$ of diabetic patients, reported 3 or more errors (table 3 ).

\section{Professionals' Point of View}

A list of typical patient errors from the professionals' point of view is shown in table 4 . The most frequent errors made by diabetic patients were related to inappropri- 
Table 5. Factors that contribute to the frequency of patient errors in the course of treatment according to professionals $(\mathrm{n}=60)$

\begin{tabular}{|c|c|c|c|c|c|c|c|}
\hline \multicolumn{4}{|c|}{ Diabetes $^{\mathrm{a}}$} & \multicolumn{4}{|c|}{ Kidney failure ${ }^{b}$} \\
\hline mean & SD & VC & $\begin{array}{l}\geq 8 \text { points }^{\mathrm{c}}, \\
\%\end{array}$ & mean & SD & VC & $\begin{array}{l}\geq 8 \text { points }{ }^{c}, \\
\%\end{array}$ \\
\hline
\end{tabular}

\section{At the patient level}

Inability to change daily habits because of the illness

Advanced age

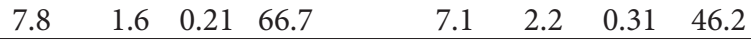

$\begin{array}{llllllll}7.5 & 1.9 & 0.25 & 48.5 & 7.7 & 1.6 & 0.21 & 38.5\end{array}$

Inappropriate beliefs about the illness and/or its treatment

$\begin{array}{llllllll}7.5 & 1.7 & 0.23 & 51.5 & 6.7 & 2.8 & 0.42 & 42.3\end{array}$

Difficulties in understanding on the part of the patient

him-/herself

Denial of the illness and its consequences

$\begin{array}{llll}7.4 & 1.7 & 0.23 & 48.5\end{array}$

$\begin{array}{llll}7.1 & 1.9 & 0.27 & 51.5\end{array}$

$\begin{array}{llll}7.4 & 1.8 & 0.24 & 42.3\end{array}$

Failure to note down the recommendations or indications of

the health professionals

Inability of the patient to carry out self-care

$\begin{array}{llllllll}6.9 & 1.9 & 0.28 & 40.6 & 6.1 & 2.4 & 0.39 & 19.2\end{array}$

Failure to come accompanied to the consultation

$\begin{array}{lllll}6.7 & 1.8 & 0.27 & 33.3\end{array}$

$\begin{array}{lllll}3.3 & 6.9 & 2.2 & 0.32 & 38.5\end{array}$

Communication barriers with medical staff (primary care or specialists)

Communication barriers with nursing staff

$\begin{array}{llll}6.2 & 2.1 & 0.34 & 25.0\end{array}$

$\begin{array}{rrrr}6.0 & 2.3 & 0.38 & 30.3\end{array}$

$\begin{array}{rrrr}6.0 & 2.3 & 0.38 & 30.3 \\ 5.0 & 2.2 & 0.44 & 9.1\end{array}$

Confusion in relation to medication (e.g. confusing pills)

$\begin{array}{lllll}5.0 & 2.2 & 0.44 & 9.1 & 4.9\end{array}$

$\begin{array}{llll}5.4 & 2.6 & 0.48 & 15.4\end{array}$

\section{At the health system level}

Faults in coordination between primary and specialist care $\begin{array}{llll}7.7 & 1.6 & 0.21 & 51.5\end{array}$

Inability to adequately transmit to the patient what he/she must

do for self-care

Faults in coordination between professionals

$\begin{array}{llll}7.2 & 2.1 & 0.29 & 51.5\end{array}$

$\begin{array}{llll}7.2 & 1.5 & 0.21 & 39.4\end{array}$

$\begin{array}{llll}6.4 & 2.4 & 0.38 & 29.6\end{array}$

Failure of health professionals to properly inform patients

$\begin{array}{llll}6.9 & 1.7 & 0.25 & 34.4\end{array}$

$\begin{array}{llll}7.4 & 1.8 & 0.24 & 48.1\end{array}$

Health professionals give information to the patient that is not

understandable to him/her

$\begin{array}{llllllll}6.8 & 1.9 & 0.28 & 33.3 & 6.4 & 2.1 & 0.33 & 25.9\end{array}$

Failure to provide timely warnings regarding medication

interactions

$\begin{array}{llllllll}6.8 & 1.9 & 0.28 & 33.3 & 6.7 & 2.0 & 0.30 & 48.1\end{array}$

Failure to inform the patients about risk signs that indicate the

need to see a professional

Divergent criteria between the GP and the endocrinologist/

nephrologist

$\begin{array}{llllllll}6.3 & 2.3 & 0.37 & 28.1 & 6.8 & 2.1 & 0.31 & 34.6\end{array}$

Absence of an effective therapeutic conciliation programme that

reduces possible medication interactions

Failure to provide sufficient privacy for patients to ask questions

and express their concerns

Increase in the number of adverse effects after returning from

holidays

Doctors saying one thing and nurses another

$\begin{array}{lllllllll}5.6 & 2.1 & 0.38 & 18.2 & 6.5 & 2.3 & 0.35 & 37.0\end{array}$

Poorly fitted catheter

\begin{tabular}{llll}
7.0 & 2.5 & 0.36 & 42.3 \\
6.3 & 2.9 & 0.46 & 40.7 \\
6.1 & 2.5 & 0.41 & 15.4 \\
\hline 5.4 & 2.9 & 0.54 & 25.9 \\
5.2 & 2.9 & 0.56 & 29.6
\end{tabular}

$\mathrm{VC}=$ Variation coefficient (ranging from 0 to 1 , where a value close to 1 implies that the professionals have different points of view on whether this aspect is a common source of errors). ${ }^{a}$ Insulin treatment. ${ }^{b}$ Dialysis treatment. ${ }^{c}$ On a scale of $0-10$; the percentage of professionals assigning 8 scale points or more to each aspect complements the information for determining which factors constitute the basic determinants of patient errors. ${ }^{\mathrm{d}}$ Error identified as relatively frequent among renal patients in dialysis in the qualitative study.

ate foot care and unsafe medication use, while renal patients' errors were related to doctor-patient communication gaps, early discontinuation of blood pressure treatment and unsafe medication use.

The factors to which patient errors were attributed according to the professionals' responses are listed in ta- ble 5 . At the patient level, their inability to change daily habits and inappropriate beliefs about the illness or its treatment were most often mentioned. At the health system level, the most frequently mentioned factors were coordination gaps among professionals and the failure to warn patients about medication interactions. 


\section{Discussion}

Confusing medicines, taking the wrong dosage, or being mixed up about doctors' or nurses' indications about medications or self-care in general were the most common patient errors. These errors are more likely to happen among diabetics. The difference between diabetic and renal patients was probably due to the more active role of diabetic patients regarding both monitoring and treatment administration.

These results suggest that routine follow-ups of these patients should include an interview about the errors detected here, with a view to their prevention. This information could contribute to the personalization of information to reduce risks when patients are using medicines or applying self-care measures.

This study adds to the causal factors of harm [13], particularly those associated with the patients themselves. While the studies on increasing patient safety have focused almost exclusively on professionals' practice, the present study highlights the large number of misinterpretations and confusions among the patients.

Evidence shows the usefulness of patient competence in self-medication, at least with regard to oral anticoagulants [14]. It might be effective to introduce the provision of systematic information on possible sources of error at home when informing patients generally, and undoubtedly in education programmes for chronic illnesses. For example, preventing common pill or dosage confusions, explaining the risk of non-adherence when a test result changes favourably or discussing inappropriate beliefs about drug effectiveness may all be effective information strategies.

The two conditions studied (diabetes and kidney failure) were selected because they had previously been identified as the two patient profiles with the highest chance of an adverse event due to their intrinsic risk factors [9, 10]. However, our study broadened the scope of this definition, since it was clear that the clinical situation increases the risk of an adverse event, but the way in which patients get involved in their own treatment can also influence the risk of harm.

We were aware that difficulties with the self-administration of insulin were common [15], but this study revealed the frequency of substantial errors not generally highlighted in the literature, such as hypoglycaemias due to dietary or medication errors, foot infections due to the wrong footwear, interactions between food and medication or among drugs, medication confusion due to similar appearances or colours, and patients' habits and daily routines that are sources of errors during self-care. Hence, these outcomes indicate that patients need more detailed information to change inappropriate behaviours. Introduction of new items of information about typical patient errors in the leaflets provided with medicines could be an alternative, especially in view of the results of other studies that have identified some deficiencies in the leaflets informing patients about precautions with the use of the drug $[16,17]$.

In contrast to the study of Al Mahdy and Seymour [6], we did not find increasing age to be associated with a greater number of patient errors. According to our data, it was the time spent receiving the treatment that determined the frequency of such errors. Nevertheless, in view of the sample size, we should be cautious with such assertions given that more in-depth exploration is required.

The results presented here also confirm the suspicions of other authors about the interrelations between patient error and scarce information provided by doctors $[7,18]$ and are an indication of the communication barriers between providers and patients. These results suggest that healthcare providers can improve information about inappropriate self-care habits related to safety.

Information on the errors most commonly made is crucial in the first stages of the illness, particularly among adolescents, among whom these figures are increasing [19]. Thus, the education package for reinforcing selfcare competence could also include information and suggestions about the most frequent patient errors and how to avoid them.

The results of this study might also serve as a guide for the informative and instructional activities of patients' associations aimed at improving safety. Indeed, in light of these and other data [20], initiatives such as these, even though they may be outside the professional healthcare context, are also relevant to the avoidance of unnecessary risks.

The results of this study should be interpreted with some caution, first because the sample sizes and sources of the samples preclude us from generalizing the results to all patients suffering from any of these conditions. The type and number of medications could modify the number of patient errors, and future studies must explore this. Second, the information provided by the patients has not been supported by objective clinical data. Furthermore, other patient conditions, such as self-efficacy, locus of control or polypharmacy (patients undergoing 5 or more different treatments), need to be explored in future studies. Also, the frequency of mistakes attributed to the professionals and to the patients themselves is probably different. In the first case, when a professional's error is reported, the report is likely to refer to situations that caused 
harm; in the second case, patients might be reporting both situations: errors or failings that had consequences and errors without consequences. Finally, there are differences between countries in the role played by pharmacists or other providers in counselling or medication education. Future studies could analyse the influence of the style or context of information given to patients by providers other than physicians and nurses.

Professionals play a very important role in patient safety, but clearly patients also have opportunities to intervene in several ways to improve it [4]. In the present study we analysed patient oversights, errors, confusions and misinterpretations and some of their causes. This first attempt to explore the frequency and nature of these types of oversights must be followed up by further research that might broaden our knowledge with the aim of drawing up better patient recommendations.

These results confirm some previous findings [21] and have some practical implications regarding the need to unify information, from professionals, to inquire systematically about other drugs prescribed by other doctors, the systematic inclusion in patient education programmes of information about possible drug interactions (with food or other medicines), the provision of clear instructions to enhance self-care and avoid misinterpretations, supply- ing help to avoid medication (drug or dose) confusion, the inclusion of new items of information in medication leaflets, and alerting patients about the most common mistakes and oversights and how to avoid them.

\section{Conclusions}

Confusions and misinterpretations are the most common patient errors. Diabetic patients have a higher chance of committing an error related to medicines. Patient attitudes and habits are the sources of the majority of errors.

\section{Acknowledgements}

This study was funded by the Health Research Fund (Fondo de Investigación Sanitaria), the Instituto de Salud Carlos III (Spanish Ministry of Science and Technology), and by ERDF, reference PI08-90118. Mercedes Guilabert and Isabel María Navarro participated actively in the preparation of and support for the qualitative techniques. Alicia Peralta helped with the data collection from patients and professionals. Jesús Casal and José Antonio Picó reviewed an initial version of the instruments for patients and professionals. Jesús Aranaz, José Francisco Herrero, José Antonio Picó, Domingo Orozco, Vicente Gil, Antonio Ochando and Encarnación Hernandez Meca participated in the data collection.

\section{References}

1 Einarson TR: Drug-related hospital admissions. Ann Pharmacother 1993;27:832-840.

2 Longtin Y, Sax H, Leape L, et al: Patient participation: current knowledge and applicability to patient safety. Mayo Clin Proc 2010;85: 53-62.

3 Schwappach DL: Review: engaging patients as vigilant partners in safety - a systematic review. Med Care Res Rev 2010;67:119-148.

4 Awe C, Lin SJ: A patient empowerment model to prevent medication errors. J Med Syst 2003;27:503-517.

5 Britten N: Medication errors: the role of the patient. Br J Clin Pharmacol 2009;67:646650.

6 Al Mahdy H, Seymour DG: How much can elderly patients tell us about their medications? Postgrad Med J 1990;66:116-121.

7 Metlay JP, Cohen A, Polsky D, et al: Medication safety in older adults: home-based practice patterns. J Am Geriatr Soc 2005;53:976982.

8 Buetow S, Kiata L, Liew T, et al: Patient error: a preliminary taxonom. Ann Fam Med 2009; $7: 223-231$.
9 Aranaz-Andrés JM, Aibar-Remón C, Vitaller-Burillo J, et al; ENEAS work group: Impact and preventability of adverse events in Spanish public hospitals: results of the ENEAS study. J Epidemiol Community Health 2008; 62:1022-1029.

10 Aranaz J, Aibar C, Limon, et al: A study of the prevalence of adverse events in primary healthcare in Spain. Eur J Public Health 2012; 22:921-925.

11 Agency for Healthcare Research and Quality: Consumers and patients. http://www.ahrq. gov/consumer/ (accessed September 2, 2010).

12 National Health Service: Practical guide to caring. http://www.nhs.uk/CarersDirect/ guide/Pages/Guidetocaringhome.aspx (accessed September 22, 2010).

13 Oyebode F: Clinical errors and medical negligence. Med Princ Pract 2013;22:323-333.

14 Hall J, Peat M, Birks Y, et al; PIPS group: Effectiveness of interventions designed to promote patient involvement to enhance safety: a systematic review. Qual Safety Health Care 2010;19:e10.

15 Grissinger M, Lease M: Misadventures in insulin therapy: are you at risk? J Natl Med Assoc 2003;95(suppl 1):1S-16S.
16 Raynor DK, Svarstad B, Knapp P, et al: Consumer medication information in the United States, Europe, and Australia: a comparative evaluation. J Am Pharm Assoc 2007;47:717724.

17 Mira JJ, Lorenzo S, Pérez-Jover V, et al: Assessment of the quality of medication information for patients in Spain. Expert Opin Drug Saf 2013;12:9-18.

18 Mira JJ, Nebot C, Lorenzo S, et al: Patient report on information given, consultation time and safety in primary care. Qual Saf Health Care 2010;19:e33.

19 Moussa M, Alsaeid M, Abdella M, et al: Prevalence of type II diabetes mellitus among $\mathrm{Ku}$ waiti children and adolescent. Med Princ Pract 2008;17:270-275.

20 Field T, Mazor KM, Briesacher E, et al: Adverse drug events resulting from patient errors in older adults. J Am Geriatr Soc 2007; 55: 271-276.

21 Ledema R, Allen S, Britton K, et al: What do patients and relatives know about problems and failures in care? BMJ Qual Saf 2012;21: 198-205. 